ISSN: $1130-3743$

\title{
PRESUPUESTOS DE LA CULTURA COMO ACONTECIMIENTO ANTROPOLÓGICO
}

\section{Premises of culture as an anthropological event}

\author{
Joaquín GARCÍA CARRASCO y Ángel GARCÍA DEL DUJO \\ Universidad de Salamanca. Departamento de Teoria e Historia de la Educación. \\ Facultad de Educación. Paseo de Canalejas, 169. 37008 Salamanca
}

Fecha de aceptación del original: 1997

BIBLID [(1130-3743) 9, 1997, 21-40]

\section{RESUMEN}

Resulta habitual encontrar estudios sobre la cultura y las relaciones entre culturas en los que se toma como punto de partida una interpretación de la misma en cuanto resultado de la acción humana, producto o patrimonio de un pueblo. A partir de ahí el análisis deriva hacia el diseño y la implementación de cuantas acciones sean susceptibles de fomentar y mejorar el desarrollo cultural de los pueblos y la dinámica relacional entre las culturas. Sin perjuicio de esta interpretación objetiva y predominante de la cultura, los autores proponen y desarrollan un enfoque diferente centrado más bien en lo que consideran como elementos y mecanismos fundamentales y básicos del suceso y del proceso cultural en el hombre. Esta perspectiva, que atiende más bien al sujeto que al producto de su acción, les lleva a proponer lo que denominan "capacidad de lectura de la mente" como característica originaria del proceso cultural humano, después de realizar un largo recorrido por algunos aspectos, unos biológicos y otros etológicos, sin los cuales el acontecimiento cultural hubiera sido imposible aunque resulten insuficientes. Los autores entienden que este enfoque no sólo resulta congruente sino también justificativo de algunas líneas de investigación que en educación están hoy intentando abrirse paso.

\section{ABSTRACT}

Quite frequently we find studies on culture and on relations among cultures in which the point of departure is an interpretation of culture as a result of human 
action, in which culture is understood as the product or heritage of a people. From this point, analysis is directed towards the design and the implementation of those actions capable of encouraging and improving the cultural development of peoples and the dynamics of relations among cultures. Independently of this objective and predominant interpretation of culture, the authors propose and develop a different approach, mainly focused on those elements and mechanisms which they consider a essential in the cultural event and process in mankind. Having first carried out an extensive study of certain aspects, some biological and some ethological (which, although in themselves insufficient, were essential for the cultural even to take place), the authors concentrate more on the subject than on the product of his action and, accordingly, they propose what they call 'ability reading mind' as an original characteristic of the human cultural process.

The authors believe that this aapproach is not only congruente but also justifies some recent lines of research.

\section{INTRODUCCIÓN}

Los enfoques predominantes en los estudios sobre la cultura y sobre las múltiples dinámicas de las que son susceptibles las relaciones entre culturas, y de las que pretenden dar cuenta los diversos prefijos que se anteponen al término (inter, multi, pluri...), suelen apoyarse en una interpretación de la cultura como "cosa", producto o patrimonio de un pueblo. Este planteamiento se aprecia con claridad cuando desde la educación se aborda el tema de qué hacer y cómo enfocar y desarrollar las acciones que desde este campo son susceptibles, al tiempo que requeridas, de llevarse a cabo en una sociedad transida de múltiples culturas, en una realidad cuya configuración se presenta progresivamente abierta.

No negamos que esta interpretación y este enfoque que entendemos predominante y necesario en nuestro tiempo sea legítimo y beneficioso; de hecho, esta perspectiva de la cultura como producto, que predominó en el siglo XIX y ha constituido la característica de los estudios antropológicos, ha aportado el beneficio de la toma de conciencia del carácter plural de la cultura humana. Pero, en nuestra opinión, el estudio de las dinámicas culturales está necesitado de un análisis previo orientado no ya a la observación, comprensión de otra cultura y fomento de las relaciones interculturales, sino a la propia descripción del proceso de configuración vital de la cultura. Antes incluso que para vivir adaptado a un entorno ecológico o social, la cultura, como veremos, resulta necesaria para poder vivir.

Los motivos por los que entendemos como conveniente y hasta previo este segundo tipo de análisis se apoyan en la consideración de que las formas de actuar educativamente para conseguir los objetivos más básicos que se persiguen en aquellos otros enfoques no deberían ignorar la explicación de lo que podemos aceptar como la génesis de la cultura, aunque para ello nos veamos obligados a realizar un viaje permanente de ida y vuelta entre lo propiamente educativo y los conocimientos que nos aportan otros campos imprescindibles en este caso, como la biología del ser humano y de su comportamiento. Al fin y al cabo, en el pro- 
ceso de configuración de un sujeto las dos dinámicas fundamentales han sido la evolución biológica y la evolución cultural, lo que somos corporalmente y lo que somos culturalmente; y este segundo componente debe aceptar un amplio catálogo de presupuestos, unos biológicos y otros etológicos o comportamentales, sin los cuales el acontecimiento cultural hubiera sido imposible. Pero todo ello sin que nos veamos abocados a una interpretación meramente biologicista del hecho cultural, pues entendemos las consideraciones que siguen como fundamentales aunque insuficientes.

Encontramos, además, un segundo motivo que justifica esta perspectiva, en esta ocasión de carácter sistemático. No llevar a cabo este tipo de análisis, desde el principio y por principio, obliga posteriormente a la investigación a buscar añadidos difíciles de armonizar cuando pretendemos, por ejemplo, presentar y enfocar pedagógicamente la denominada educación ambiental, el papel de la sensibilidad, el lugar de la comunicación corporal... o las formas de pensamiento e inteligencia; en cambio, el planteamiento que nos proponemos desarrollar hace justicia, en nuestra opinión, con aquellas exigencias y las deja ya previstas.

\section{Presupuestos básicos, PeRo insuficientes, De la CUltura}

\subsection{La cultura es una acontecimiento vital}

El suceso cultural acontece necesariamente en un ser vivo. En la perspectiva más básica que puede adoptarse, el acontecimiento cultural primordial dice relación a necesidades vitales y a la forma como el individuo responde a esas demandas: la necesidad de procreación, de la crianza, de la búsqueda en el medio del alimento necesario, de la demarcación y construcción del espacio vital imprescindible y, en definitiva, la necesidad de asegurar la permanencia de la especie y del grupo. Estas líneas primarias de orientación del comportamiento reflejan la corporeidad y sus manifestaciones, sin duda, pero aquí la dotación genética de capacidades de respuesta no se encuentra, en general, cerrada (estímulo-respuesta) sino abierta, flexible, moldeable y adaptable; si no quedara afectada por configuraciones comportamentales dirigidas y transmitidas culturalmente, cual es el caso del abandono total, el individuo, si lograra sobrevivir, no sería antropológicamente reconocible.

El hombre es un ser vivo y en cuanto tal identifica los caracteres del medio que le permiten reconocerlo como fuente de satisfacción de una necesidad, pero además, ese ser vivo que es el hombre se encuentra necesariamente inserto en tramas de significación que él mismo construye. Aquí, la explicación de un comportamiento meramente por la línea de las causas, como en los entes físicos, resulta insuficiente, pues hacen su aparición las razones, v. gr., el ataque o la huida no será el efecto de una reacción entre componentes físicos de una estructura corporal y un componente del entorno, sino la consecuencia de percibir una amenaza. De ahí que la cultura, en el caso humano, se comprenda mejor como sistema de mecanismos de control personal de acción (planes, reglas, instrucciones...) que como catálogo de pautas. 
Toda especie de organismos, en la complejidad variable que constituye su genoma, posee la oportunidad de acceder a alternativas, trucos de sobrevivencia que aparecen en el etograma de su comportamiento y en función de los que aquélla se hace posible en entornos que también cambian, modificando ante el organismo las condiciones para el éxito de la permanencia de la especie. El principio fundamental en este sentido es el de la coderiva del organismo con el entorno, lo que implica cambios en la estructura y cambios en el comportamiento.

Cuando decimos que el suceso cultural acontece original y originariamente en corporeidades, este enunciado plantea el problema de la relación entre el genoma o programa que proporciona y reproduce la estructura del ser vivo, el comportamiento y las posibilidades de cambio en el comportamiento, pero dicho enunciado no se reduce a lo que suele denominarse genética del comportamiento o innatismo del comportamiento, sino que hablamos de la susceptibilidad constitutiva y constituyente del organismo a modelar el comportamiento como consecuencia de procesos de transacción con el entorno y, en nuestro caso, como consecuencia del aprendizaje. En cualquier caso, si el hombre no fuera un ser vivo, no sería sujeto de cultura; a lo que hay que añadir inmediatamente que, aunque esta condición vital resulte necesaria, no es todavía suficiente.

\subsection{La cultura responde a la necesidad vital de información}

No es posible comprender un organismo en tanto que estructura con genotipo sin los bloques estructurales procedentes del entorno (nurture), como tampoco el entorno posee significación sino en tanto que "reconocido" por el organismo (nature) como bloque en una transacción alimenticia, perceptiva o activa; ni el determinismo genético ni el determinismo ambiental dan realmente cuenta de los fenómenos observados. El ser vivo sólo puede aparecer cuando el fenómeno de la clausura demarca los dos polos de una interacción en la que el organismo detecta, procesa y almacena información mediante la cual es capaz de reproducirse y desarrollarse; la información es el componente que posibilita su permanente estado de desequilibrio, cambio, evolución.

Dicha información no es meramente materia o energía, sino que siempre tiene que ver con el hecho de la estimulación, es decir; tiene que ver con materiales (v. gr., moléculas o compuestos alimenticios, otros organismos...), con energía (v. gr., ondas sonoras, ondas luminosas...), pero también con presencias, ausencias, señales, signos, significados. Para cada individuo de cada especie tan sólo fracciones estructuradas del entorno producen los acoplamientos necesarios para constituirse en estimulación, sólo un número limitado de sucesos en el entorno adquieren la condición de información para un ser vivo. Podríamos decir que en términos de organismo la única información existente es la que tiene para él vitalmente sentido (para bien o para mal), la utilizable en términos de funcionamiento (para bien o para mal) o de comportamiento. Por esta vía, tanto para los organismos que denominamos sencillos como para los complejos (aunque la vida es el reino de la complejidad), se reconoce la partícula alimenticia o la presencia de una hembra en el momento adecuado para la fecundación, se advierte y comu- 
nica la presencia del depredador o de un competidor en el nicho ecológico, se coopera en la obtención del alimento o en el cuidado de las crías... La presencia de un mismo estímulo se constituirá, pues, en un determinado bloque de información en correspondencia estructural con un receptor y de su correspondiente capacidad estructural de respuesta (patrón de comportamiento) ${ }^{1}$.

Todos los organismos disponen en su estructura de sistemas de recepción y procesamiento de información especializados, tanto respecto del medio externo como del interno; unos se encuentran situados en la cobertura, como la extraordinaria variedad de receptores sensoriales, otros son interiores y calibran los diferentes estados de funcionamiento. Estos sistemas de detección, transformación y almacenamiento de información permiten discriminar, por ejemplo, un gradiente de humedad o temperatura (en la raíz de una planta o en un organismo unicelular en un fluido) o identificar una cría entre los miles de ellas que chillan al mismo tiempo en la zona de reproducción de una especie de aves.

Entre los sistemas de almacenamiento, elaboración e integración de la información sobresale por su complejidad el Sistema Nervioso Central de los organismos calificados coloquialmente de superiores por la calidad de sus elaboraciones y por la capacidad de reelaboración de la información almacenada para producir lo que denominamos, especialmente en el hombre, la creatividad del comportamiento. Y, aunque el SNC contiene también mecanismos de comunicación acerca de estados internos y de oportunidad de comportamiento en el medio, también se encuentra el sistema hormonal para favorecer, por ejemplo, el proceso vital de la cópula, de la muda, de la deposición de los huevos o de la incubación.

Pues bien, sean cuales fueran los mecanismos y sistemas, la intercomunicación entre organismo y entorno así como entre organismos es condición necesaria para el acontecimiento cultural, aunque también, como en el epígrafe anterior, resulte insuficiente.

\subsection{La cultura es un acontecimiento en los sujetos}

En el proceso permanente de acoplamiento estructural entre organismo y ambiente (auto-ecopoiesis) ${ }^{2}$ el suceso cultural aparece siempre como diciendo relación a sujetos; esta perspectiva no queda recogida suficientemente o resaltada con suficiente claridad por el concepto ampliamente utilizado de patrimonio cultural, sobre todo cuando se focaliza en la línea de los productos culturales, provocando la inhibición del sujeto en el análisis. Los productos culturales radicalmente segregados del sujeto carecen de sentido; los discursos culturales no pueden, de ningún modo, separarse de los actores. Conservar el patrimonio de los pueblos constituye un hecho cultural sólo en la medida en que se erige en signo y símbolo desde y para la elaboración de un actor.

1. No son pues las meras palabras "estímulo", "respuesta", "información" sino su posición de significado en el interior de una teoría (v. gr., el conductismo) las que pueden tergiversar el significado vital de la interacción individuo-entorno.

2. Maturana, H. y Varela, F. (1990): El árbol del conocimiento. Las bases biológicas del conocimiento bumano. Editorial Debate, Madrid. 
Los seres vivos, en contraposición con los seres físicos, hacen, actúan en el entorno. Y aunque suele denominarse comportamiento a la interacción entre entes físico-químicos (el comportamiento del bicarbonato de sodio con los jugos gástricos del estómago), el término comportamiento funciona aquí como una metáfora. Comportamiento propiamente dicho es lo que tiene lugar en la actividad de los seres vivos en la medida en que dicha actividad ha sido aprendida por interacción-aprendizaje con otro/s miembros de su misma especie; de ahí que el comportamiento social constituya otro fundamento de la cultura.

La habituación como proceso puede reducir, por ejemplo, el comportamiento de huída de las palomas ante la presencia humana, habitúa a los chimpacés al trato con sus cuidadores; el condicionamiento operante que refuerza una conducta que aparece aleatoriamente termina por hacer aprender patrones de comportamiento a ratas, palomas, animales de zoo o de circo; el aprendizaje exploratorio es observable en muchos mamíferos y animales domésticos. Muchas especies de aves no desarrollan su capacidad de canto de forma completa hasta que no escuchan el de otros ejemplares adultos, desarrollando incluso dialectos de canto particulares dentro de poblaciones territoriales. Muchos otros animales interactúan con miembros de la misma especie y en esa interacción aprenden, imitan; ésta es nuevamente una condición necesaria de la cultura, aunque tampoco resulte suficiente para la descripción del suceso cultural humano.

\subsection{La cultura es un proceso social}

En efecto, otro de los fundamentos de los sucesos culturales viene dado por la aparición del patrón cooperativo, que se alcanzó en la evolución mucho antes de la aparición del hombre y que, como cualquier otro patrón de comportamiento, surgió y evolucionó regulado por el código genético. Pero la noción precisa de cultura, la originalidad del proceso para el que se construye el término, no dice relación tanto a lo que los organismos saben hacer, aunque constituya su fundamento, cuanto a la vía o canal mediante la cual han conseguido crear la disposición para llevarlo a cabo. El modo como las aves o los peces de especies migratorias consiguen retornar a los lugares de anidamiento recorriendo grandes distancias requiere de complejos procesos de reconocimiento, cuya descripción exige al hombre complicadas investigaciones y que, sin embargo, ellos realizan por ejecución de programas de comportamiento regidos por su sistema genético. La cultura designa, precisamente, el proceso mediante el cual una disposición y habilidad de comportamiento pasa de una generación a otra mediante procesos de aprendizaje social; dice más relación al proceso de cultivar (educar-formar) que al producto del cultivo. De ahí que la cooperación en cuanto tal, como en el caso de los insectos, no signifique cultura en el sentido humano, sino en la medida en que aquélla se aprende y lleva a cabo en el interior de un proceso de socialización. Los insectos sociales, por ejemplo, no son sociales por haberse socializado, sino porque son así de cooperativos y no pueden ser de otra manera, sin cambiar su estructura fenotípica y genotípica. La constitución de comunidades estables se observa en muchas especies, especialmente entre los insectos, incluso puede 
observarse también la aparición del pequeño núcleo familiar, que lo hizo en la evolución mucho antes que el hombre; el patrón cooperativo se advierte incluso entre especies no emparentadas, así como la distribución de funciones y la jerarquización del grupo, sirviendo su sistema de comunicación para la coordinación de las relaciones y las funciones del grupo, evitando las luchas violentas para el mantenimiento de las diferencias... La presencia de este patrón cooperativo, la existencia de comportamiento socialmente organizado es condición necesaria para el acontecimiento cultural, pero es insuficiente.

\subsection{El suceso cultural genera productos culturales}

La mayor parte de los organismos interactúan con el medio produciendo en él transformaciones que en sentido estricto lo preparan para su utilidad; algunas de estas transformaciones, las que implican la selección y construcción de un hábitat para vivir, sorprenden por su nivel de complejidad y elaboración: el panal de las abejas con la perfección de sus celdillas, las cuevas laberínticas pero departamentalizadas de las termitas, la maravillosa tela de araña, las huras, los nidos... Incluso unos animales pueden aprovechar las transformaciones de otros en su propio beneficio. Más aún, algunos animales insertan artefactos dentro de patrones de acción corporales, mejorando la eficacia de su comportamiento. La herramienta, que fue para algunos hace tiempo la clave cultural para diferenciar a la especie humana, perdió definitivamente tal categoría cuando se observó que la nutria marina rompe con una piedra los moluscos mientras flota, que el pinzón emplea la púa de acacia para urgar en el agujero de la larva en el tronco de un árbol o que el chimpancé y el gorila emplean habitualmente varios útiles, según el entorno. En sentido propio, hablamos de producto cultural cuando la utilidad creada en el entorno se inserta en un proceso de aprendizaje social para aprender a realizarla, a utilizarla o a interpretarla. También esta habilidad constructiva del entorno y en el entorno es condición necesaria para la cultura, pero tampoco es suficiente.

¿Cuál es, pues, el componente distintivo del suceso cultural humano? En el acontecer cultural humano se advierte la presencia de un rasgo distintivo, que no se ha observado en ninguna otra especie animal, el cual modifica cualitativamente todas las capacidades observadas en las demás especies: los seres humanos tienen la capacidad de "lectura de la mente"; poseen, a partir de un cierto momento en su nivel de desarrollo, la capacidad de comprender la intención del otro, de manipular las condiciones ambientales para promover la intención de acción en el otro en la dirección de la propia intencionalidad. Pero, para desarrollar más ampliamente el contenido de esta capacidad, consideramos imprencindible un análisis más profundo del sistema de comunicación humana, partiendo de un análisis del concepto de información y de la comunicación biológica.

\section{LA INFORMACIÓN EN EL MUNDO DE LA VIDA Y EN EL MUNDO DE LA CULTURA}

La preponderancia que han tomado en estos últimos años las ciencias de la información y de la cognición ha subrayado de manera especial lo que la cultura 
tiene de proceso de transferencia y apropiación de significado; Jesús Mosterín entiende a este respecto que la cultura es la información transmitida por aprendizaje social ${ }^{3}$, dando preferencia al componente de proceso más que a los resultados, como nosotros hemos resaltado, y situando el concepto de transmisión cultural, tan genuinamente pedagógico, en el corazón mismo del sistema conceptual de la Antropología de la Educación. Pero, de la misma manera que un mismo proceso biológico, por ejemplo la nutrición, es compatible y coherente con la existencia de diferentes géneros y especies animales y, por la misma razón, con diferentes clases de nutrición, también el proceso de transmisión de información contiene en sí géneros y especies diferentes, diferencias categoriales entre las distintas esferas de la vida animal y diferencias cualitativas cuando la transmisión de información tiene lugar en el interior del proceso de la cultura humana. Puesto que la vida es información, de la misma manera que se dan diferentes especies de vida, también se dan diferentes especies de información; esas diferencias de especie en la información tienen mucho que ver con diferencias en la complejidad de los organismos que se comunican. Dicho en otros términos, siendo cierto que la información constituye el elemento básico y componente funcional que mantiene ensamblado al organismo, conectándolo con el entorno, es éste, sin embargo, un concepto cuya interpretación en el interior de una teoría, al tiempo que descubre el fenómeno, lo encubre; de ahí que la transferencia del concepto y su significado de un campo fenoménico a otro implique riesgos, si no se tienen en consideración las características específicas del proceso de transmisión de información en cada campo. Conviene, por tanto, que nos detengamos en el análisis de las formas variadas que puede adoptar ese proceso de transmisión de información o acción de comunicación.

\subsection{La teoría matemática de la información}

Puede considerarse que el término información queda introducido en el ámbito científico cuando R. Hartley ${ }^{4}$ construye en 1928 la medida cuantitativa de la capacidad relativa de transmisión de sistemas eléctricos; dicha medida es de carácter logarítmico y recoge las decisiones binarias imprescindibles para caracterizar de manera inequívoca un sentido del mensaje, siendo denominada información ${ }^{5}$. Se parte del supuesto de que, antes de la selección de cualquier estado del mensaje, la probabilidad de su selección es menor que cien; después de seleccionado, ésta se transforma en cien. El cambio de probabilidad para el receptor es la cantidad de información transmitida; la información es, pues, el cambio en las probabilidades del receptor, como consecuencia de la selección real de un estado de mensaje entre los que eran probables. La unidad "bit" representa la cantidad de

3. Mosterin, J. (1993): Filosofia de la cultura. Ed. Alianza, Madrid, p. 21.

4. HaRTLEY, R.: "Transmission of information", Bell System Tecbnical Journal, 7 (1928), 535-563.

5. Esta noción fue sometida a desarrollos posteriores. Cfr. SHANNON, C.: "A Mathematical Theory of Communication", Bell System Technical Journal, 27 (1948), 379-423, 623-656. WIENER, N. (1948): Cybernetics, Nueva York, John Wiley \& Sons. Brillouin, L. (1956): Science and Information Theory. Nueva York, Academic Press. 
información para distinguir entre dos alternativas, estados de mensaje, equiprobables; aunque hablamos de información, en rigor estamos ante una medida de incertidumbre.

Desde un punto de vista técnico, los problemas que aquí se presentan y se estudian son los siguientes: la cantidad de información, la capacidad del canal de comunicación, el proceso de transformación de mensaje en señal de comunicación y su inversión de señal a mensaje (proceso de codificación-decodificación) y los efectos del ruido o interferencia sémica.

La teoría de la información, en sentido estricto, no hace la menor referencia al significado, sino al carácter probabilístico del conjunto global de mensajes dentro de un sistema de comunicación 6 ; es ésta, pues, una teoría formal y a nosotros nos interesa una teoría material o factual en el sentido de incluir procesos específicos y/o significativos. Pero, no obstante ser una teoría matemática de la información que inhibe el significado, ha sido el fundamento del desarrollo de la denominada era de las comunicaciones con sus consiguientes efectos culturales.

Aquella teoría formal tuvo dos proyecciones pedagógicas inmediatas: aplicación del aparato conceptual al análisis de procesos de enseñanza-aprendizaje (simulación) y la construcción de máquinas para enseñar que seguían el criterio de los pequeños pasos y elaboraban las secuencias siguiendo los puntos de vista del conductismo7. Y a veces se olvida que la innovación fundamental estriba en el hecho de tomar como soporte de la comunicación la huella electromagnética. La primera innovación fue el lenguaje proposicional, que genera todas las formas culturales de oralidad; hasta ese momento había sido la comunicación estructural o la comunicación corporal, todo cambio de forma o posición con una enorme gama de categorías de señales y un alto nivel de elaboración. La segunda gran innovación fue la aplicación de la función gráfica a la composición de mensajes y su posterior asociación con el lenguaje proposicional, que da lugar a todas las culturas lectoescritoras. La tercera ha sido precisamente la aplicación de la señal electromagnética a procesos de comunicación en los que pueden quedar asociados todos los sistemas de comunicación, excepto los que impliquen contacto material, como la comunicación química o la comunicación táctil. Son los denominados instrumentos multimedia, en los que el soporte no es el sonido ni el gesto, tampoco un soporte físico flexible-plegable, sino una máquina que reproduce ampliamente las condiciones de la mayor parte de los sistemas anteriores al tiempo que pro-

6. Bueno, G. (1996): "Información y causalidad", en Caffarel SERra, C. (comp.): El concepto de información en las Ciencias Naturales y Sociales. Ed. Universidad Complutense, Madrid. Cita la conocida obra de Bar-Hillel en la que afirma «los aspectos semánticos de la comunicación son irrelevantes para los problemas de la ingeniería". Con ello, indica G. Bueno, "prescinde de los contenidos de realidad y de verdad"; nosotros añadiríamos que estos aspectos forman parte esencial de la comunicación implicada en los sucesos culturales.

7. De la aplicación teórica de la cibernética tenemos como ejemplo la obra de Frankc, H. G. y Meder, B. S. (1976): Introducción a la Pedagogía Cibernética. Ed. Troquel. Quizás el pionero más significativo en España haya sido Alejandro Sanvisens Marfull, maestro de muchos de nosotros. De las aplicaciones de los ordenadores a procesos instructivos todavía estamos simplemente viendo el amanecer de las iniciativas, las cuales no tienen nada que ver con aquellas primeras máquinas de enseñar. 
porciona otras oportunidades diferentes. Con ello queremos decir que, con independencia de los términos iniciales de la Teoría de la Información y sus limitaciones, este campo ha terminado por constituir un producto-fuente de productos culturales entre los que cabe destacar el aumento prácticamente ilimitado de las posibilidades de cómputo, la posibilidad de simular procesos así como la creación de un nuevo contexto de comunicación no presencial.

\subsection{La comunicación biológica}

En el epígrafe anterior el vehículo de la comunicación es una señal, pero el modo básico de comunicación mediante secuencias de señales, canal y receptor no es el único modo de acontecer de la información. Desde el punto de vista biológico-informacional, en la forma más elemental de comunicación organismoentorno u organismo-organismo, lo que llega y conecta con el receptor no son señales sino estructuras que lo hacen por vía de acoplamiento entre el estado de la estructura del receptor y aquélla con la que conecta del emisor; tal es el caso de todo el proceso de conexión entre la partícula alimenticia y el ser unicelular, contacto que empieza por un reconocimiento a través de la membrana, así como el proceso de reconocimiento que lleva a cabo el sistema inmunitario. Muchos animales adoptan este sistema, y lo perfeccionan como un auténtico sistema de comunicación entre individuos de la misma especie, para ejecutar procesos vitales en los que tienen necesidad de implicarse individuos diferentes, v. gr., la reproduccion sexuada entre mariposas en la que el macho sigue a la hembra guiado por su rastro de feromona. Es esta información la que cumple de manera más estricta con la definición teórica de información, puesto que consiste precisamente en el cambio de probabilidad en la secuencia de estados de las estructuras comunicadas; a este tipo de información se le denomina información sintáctica o información estructural.

Incluso en este género sintáctico de comunicación conocemos diferentes clases de estructuras de significación, especies diferentes de información sintáctica, diferentes clases de sintaxis: de composición, como la información que transmite el ADN mediante reglas de composición ${ }^{8}$; de organización, como la información que tipifica el hígado humano en función de su estructura organizacional; de disposición espacial, como la que puede observarse en las proteínas, etc. En todas ellas se descubre una función de interacción que denominaríamos, con Edelman ${ }^{9}$, de reconocimiento, de identificación de lo que es y de lo que no es, pero estas diferentes especies de sintaxis son primarias o elaboradas por mecanismos adaptativos de la evolución y la información originada así, sea cual fuere la variedad sintáctica, no fue suficiente para la construcción de un

8. Incluso en este nivel tan fundamental del comportamiento orgánico los procesos de información que tienen lugar son cualitativamente diferentes en función de los componentes afectados. OCHANDo GonZÁlez, M. D. (1996): “Información, genética y evolución”, en CAFFarel Serra, C. (comp.): El concepto de información en las Ciencias Naturales y Sociales. Ed. Universidad Complutense, Madrid, pp. 41-63.

9. Edelmar, G. M. (1994): Biologie de la conscience. Editorial Odile Jacobs, Paris. 
suceso cultural. Otras formas de sintaxis están asociadas a códigos construidos, formando los denominados sistemas de comunicación.

\subsection{La información a través de la comunicación}

Aunque el estudio de la comunicación animal revela la imposibilidad de penetrar fenoménicamente y en su totalidad en un campo comunicacional con los sistemas de comunicación de otro ${ }^{10}$, cabe la posibilidad de hacerlo por vía indirecta. Desde esta perspectiva, y reconociendo de antemano el carácter antropomórfico de muchas de nuestras descripciones etológicas, es posible, y sobre todo resulta útil para el progreso de nuestra reflexión, aceptar que la relación y comunicación entre el ser vivo y su entorno se fundamenta, apoya y manifiesta ante todo en y a través de la acción; relacionarse, comunicarse con-en el entorno es, ante todo y en primer lugar, actuar en él. Y pueden advertirse diferentes formas de comunicación-acción, por ejemplo, cuando una misma acción resuelve varias situaciones ambientales (función extensiva), caso predominante en los órdenes inferiores de la escala animal; cuando, como resultado de la ampliación del etograma animal, aparecen respuestas del organismo a solicitaciones ambientes y entre ambas se da una relación biunívoca (función intensiva) o cuando, por poseer un repertorio comportamental más rico, flexible, incluso con la plasticidad que otorga el aprendizaje, el animal tiene que elegir y la situación ya no es simplemente desencadenante sino que es atendida y dicha atención es selectiva desde el momento en que debe elegir. La acción que se selecciona supone cierta estimación y expectativa de la consecuencia así como también queda incluida en selección la atribución de un cierto valor subjetivo-ecológico a la acción seleccionada, indicando todo ello que la atención selectiva, la selección de la acción, el significado y la función propositiva forman una unidad de estructura11.

Se aprecia en este último caso que la acción en el entorno de los organismos ha evolucionado desde los acoplamientos de estructuras, en los que la interacción organismo-entorno se fundamenta en la causalidad física, a la interacción mediada por señales; desde la afloración conductual de estados internos a la comunicación social con metas definidas. Pues bien, a la información que se origina en la correlación entre una clase de señales y un estado, acontecimiento, del propio emisor o respecto a cualquier otro componente del entorno se le denomina información semántica. El desarrollo de este sistema de información en el reino animal se produce en conderiva a la propia evolución del patrón de cooperación en todas sus formas.

Dentro de esta comunicación semántica en el ámbito animal encontramos clases diferentes en función de las consecuencias que inducen y las condiciones bio-

10. Riba I CAMPos, C. (1996): "Comunicación animal y significado: bases para una zoosemiótica", en CAFARel Serra, C. (comp.): El concepto de informaicón en las Ciencias Naturales y Sociales. Ed. Universidad Complutense, Madrid.

11. "Así pues, la intención, como el significado, es un valor natural derivado de la misma funcionalidad del organismo y la conducta". Ibidem, p. 91. 
lógicas que requieren: hay correlaciones señal-señalado-reacción del receptor que son rígidas, cual es el caso de la mayor parte de los sistemas de señales que se emiten o procesan dentro de los sistemas de comunicación animal, por más que aquí no todo es tan rígido como en las estructuras de la física, puesto que son seres evolutivos en los que con el tiempo cambia tanto la estructura como el comportamiento. Un aspecto importante de estos sistemas de comunicación viene dado por el hecho de que no sólo implican estados físicos y cambios cuantitativos en los sistemas biológicos, sino que también quedan afectados estados cualitativos globales del organismo; es el ámbito de la sensibilidad-emocionalidad. Esta innovación comunicacional, cuya evolución y elaboración se asocia al SNC, perfecciona el sistema comunicacional hasta llegar a la antesala de la comunicación humana; pero la semanticidad ya puede observarse en muchas especies animales.

Las mustelas tienen un "silbido de aviso... Cuentan también con un gruñido áspero, de tono más grave en los animales de mayor tamaño, y un grito que hiela la sangre y que, por fortuna, no emplean más que en contadas ocasiones. El gruñido no es para intimidar, pero lo profieren asimismo en el combate y supone siempre un indicio de furia o de mal genio. El grito es una indicación de que la mustela se halla en mortal agonía, que siente un miedo cerval o una rabia incontenible, como cuando le roban la comida" 12 .

Pero también se dan correlaciones construidas, por ejemplo, por condicionamiento, como el animal al que se habitúa a percibir la correlación entre una señal neutra y la presencia del alimento. En estas clases de información semántica la noción de receptor debe completarse con la de observador; las especies que pueden construir este tipo de conexiones no solamente perciben sino que también observan, exploran el entorno en busca de información vital para la que se encuentran en estado de alerta.

\subsection{La información pragmática}

Mientras el realismo ingenuo estima que el referente de la acción viene dado por algo exterior, un objeto o acontecimiento del entorno al que queda referida directamente la acción, nosotros entendemos que el referente de la acción de comunicación se encuentra en el núcleo del significado, modulando el suceso al tiempo que activa la motivación, el afecto, la experiencia anterior, el aprendizaje... del observador; el observador no sólo percibe sino que también clasifica y en los animales sociales esa implícita interpretación desencadena consecuencias.

A esta modalidad de información referencial se la denomina información pragmática, aquélla en la que se construye el significado en función de la interpretación que de la misma haga el observador, y que, a su vez, depende del estado subjetivo que presente, v.gr., una hembra amamantando a sus cachorros puede manifestar una agresividad inusitada ante la proximidad de sus amos por interpretarlo como amenaza dentro de unos umbrales de sensibilidad mucho más exi-

12. Brown, V. (1995 v.o. 1955): Los lenguajes secretos de los animales. Ed. RBA, Barcelona, p. 66. 
gentes. Dentro de esta modalidad se dan también diferentes categorías: información declarativa, en función de la cual se identifican datos acerca de lo observado; información procedimental, en la que se encuentra implicadas las habilidades, las secuencias de acción, las destrezas, los patrones de comportamiento y, finalmente, información valorativa, por la que se elaboran sentimientos de valor asociados a parámetros emocionales de origen adaptativo o aprendidos.

La evolución de la información pragmática ha llevado incluso a la coordinación de acciones en lo que atañe a la inserción de objetos en programas de acción $\mathrm{y}$, por lo tanto, empleados como instrumentos para el logro de determinadas funciones vitales, como se aprecia en el comportamiento de muchos animales; respecto a los útiles empleados el animal no recibe más señal que la del reconocimiento de su utilidad. Para el suceso cultural resulta imprescindible la posibilidad de comunicación pragmática, pero esta clase de información pragmática no es suficiente para el acontecimiento cultural humano.

Ha sido necesario realizar este recorrido para remontar aquellas tendencias que atribuyen el significado únicamente a contenidos de mensajes preponderantemente orales o aquellas otras que analizan la información solamente por la vía del signo independientemente del mensaje. Pero lo verdaderamente sugestivo es comprobar que todas esas modalidades de transferencia de información se incluyen y reconstruyen en contexto humano: la estructura y secuencia de un proceso, la distensión del mismo en el tiempo, la movilidad en el espacio, la configuración organizacional, la comunicación química... que han sido soportes de información se tornan en el espacio humano en fuentes y soportes de significado.

\subsection{La acción comunicativa bumana}

Resulta muy frecuente encontrar análisis de la acción comunicativa humana realizados con base en la aplicación del modelo de Shannon y Weaver: un mensaje que se transmite por un canal, la metáfora del tubo. Esta imagen, potenciada por los medios de comunicación, ha terminado por distorsionar la visión de la acción comunicativa en el ser humano, además de demostrarse falsa en el análisis de la comunicación biológica, como hemos demostrado en los epígrafes anteriores. Fernando Broncano ${ }^{13}$ hace caer en la cuenta de que, aun sin la existencia de una teoría bien definida, hoy confluyen varios planteamientos cuyo denominador común pone de manifiesto la insuficiencia de ese modelo para dar cuenta de la acción comunicativa humana. Ni el signo es el único elemento primario, también lo es la situación; ni el lenguaje es el único modo de comunicación, sino uno entre otros. La regla general que funciona en la acción comunicativa humana viene expresada, ante todo, por la ruptura de la norma de correspondencia biunívoca entre los indicios y la construcción del significado en el observador; en la denominada semántica situacional, la situación de emisión y la situación de obser-

13. Broncano, F. (1996): "Información, comunicación y sistemas informativos", en CafFarel SERrA, C. (comp.): El concepto de información en las Ciencias Naturales y Sociales. Ed. Universidad Complutense, Madrid, pp. 262-280. 
vación anteceden al suceso comunicacional: "la obtención de información consiste en una interpretación de la situación de emisión, antes que en la decodificación de un mensaje neutro" 14 .

La acción comunicativa humana contiene una coordinación de acciones que proponen información y de intenciones de significación que requiere del observador la atención selectiva a tal complejo. Decimos que la acción comunicativa funciona como un complejo compuesto por la coordinación de acciones e intenciones, plateamiento éste diferente al del enfoque lineal que se desprende de la imagen tubular mensaje-código-canal, puesto que los elementos significantes que los actores utilizan se corresponden no sólo con códigos sino también con movimientos y cambios de forma, manipulaciones del contexto, de las circunstancias... en vistas a activar y disponer la situación, atención e intención del observador en sintonía con las del actor; como afirma el autor de referencia, el modelo emisorcanal-receptor, más que ayudar, limita y hace opaca la visión.

La especie humana, junto a los productos culturales objetivos, cuenta con la adquisición de todo un conjunto variado de estrategias de comunicación y manipulación de circunstancias; algunas tienen su origen en el etograma primario de la especie, pero la inmensa mayoría se aprenden a medida que se va produciendo interacción en el entorno activo influyente. La puesta a punto de este sistema de interacción social parece ser el proceso más importante desde el punto de vista cultural y educativo del desarrollo humano después del nacimiento y todo parece indicar que no se encuentra a punto hasta los cuatro años. En todas las demás especies la dinámica evolutiva consistía en la interacción estructural con el ambiente natural físico-biológico; la dinámica evolutiva que termina en el hombre y la dinámica específica de éste, por encima incluso de la interacción con el ambiente, se centra más bien en la dinámica de interacción social. Los retos sociales han sido evolutivamente más importantes que los ambientales; el éxito reproductivo cayó más del lado de las habilidades sociales que de las habilidades ambientales.

"Los problemas que ofrece la existencia de otros seres de la misma especie es mucho más importante cualitativa y cuantitativamente que los propuestos por el medio ambiente 'natural', por hostil que éste pueda parecer. Fue así desde que los homínidos siguieron una senda evolutiva en la que el agrupamiento en bandas jerarquizadas se convirtió en su principal instrumento de supervivencia. Se ganó en seguridad y en tiempo de encontrar alimentación, pero también se ganó una nueva fuente de problemas: cómo ajustar la propia conducta a la conducta de los otros. En algún momento comenzó a primarse evolutivamente a los individuos capaces de manipular la conducta de los otros manipulando su mente, bien mediante el engaño, como sostiene la hipótesis maquiavélica, bien mediante la expresión de los propios deseos y la insistencia en la comunicación, como sostiene la hipótesis cooperativa (roussoniana)”15.

La acción comunicativa implica, pues, en la especie humana no sólo el suceso mental de la intención de que nuestra acción muestre nuestras intenciones

14. Ibidem, p. 268.

15. Ibidem, p. 270 . 
- desde la intención de informar sobre cosas, organismos, personas, a la intención de expresar nuestros estados de ánimo-, lo que exige en el actor un proyecto de organización de la acción en vistas a su transparencia comunicativa, lo que equivale, a su vez, a ponerse en el lugar del otro respecto a uno mismo, la comprensión de las circunstancias de la acción y la interpretación de las circunstancias de la interpretación, sino también la intención de producir en la mente del otro el cambio que supone interpretar mi acción en función de mi intención, poner la mente del otro en la dirección de mi proyecto de acción.

La acción comunicativa humana es, pues, trialógica, no es meramente enunciativa. No somos humanos porque seamos capaces de recitar un poema en un bosque solitario, sino porque somos capaces de tener la intención de cambiar la intención del otro manipulando la acción y las circunstancias de la acción. La acción comunicativa se compone de la tríada actor-situación-observador y su dinámica no es lineal sino circular, revierte en el actor confirmando y replanteando; todo ocurre dando a entender que el significado es progresivamente consensuado, entendido.

La acción comunicativa así entendida constituye el embrión de la cultura en cuanto que lo es de la educación del comportamiento. Las estrategias de la educación son en el fondo estrategias de comunicación (comprensión de las intenciones) y de manipulación de circunstancias para producir cambio en el otro (orientación de su acción en la dirección de mi intención). El estudio de estas secuencias complejas en situaciones diversas y con intenciones definidas respecto a proyectos de acción diferentes es el núcleo de la Teoría de la Educación; la adquisición de competencia, la construcción de reglas, el diseño de planes, la creación de artificios como consecuencia de la actividad mental de reflexión sobre aquellos procesos configura el proyecto de la Pedagogía como campo de estudio.

Pero, si no andamos descaminados al describir la acción comunicativa como lo hemos hecho, no solamente la interacción entre actores y el contexto de acciónobservación son los únicos elementos relevantes; los medios o mediadores de la comunicación adquieren una importancia de primer orden en cuanto que en algunos casos modifican las categorías de tiempo y espacio a la vez que permiten la creación de nuevas situaciones o realidades. En esta perspectiva la introducción de los sistemas tecnológicos de la información y comunicación responden a la necesidad natural de información en el ser humano, necesidad que va más allá de la simple curiosidad por estar informado para adentrarse en la necesidad misma de comunicación para la acción y para la evolución y desarrollo de la capacidad de acción; los seres humanos necesitan oportunidades de acción como consecuencia de la interacción con los demás en el mundo y, en este sentido, los seres humanos necesitan la cultura para vivir.

\section{El estado de la mente en la Cultura}

Cuando se observa la actividad de muchos animales y las características de su comportamiento y modalidades de su comunicación, sobre todo en los animales denominados superiores, resulta difícil sustraerse a la impresión de que también 
se les puede aplicar con toda propiedad la característica de poseer actividad mental. Pero ¿qué estado debe alcanzar en sus operaciones tal actividad mental para ser plenamente susceptible de actividad cultural y no andar meramente en el umbral de los puros indicios? Aunque la respuesta es obviamente compleja, nos concentraremos en una propiedad que atrae en este momento la coincidencia de muchos investigadores; nos referimos a lo que se denomina reconocimiento de estados mentales en los otros ${ }^{16}$, lectura de la mente del otro o poseer una teoría de la mente. Lo denominamos teoría porque supone la elaboración de inferencias sobre estados de cosas mentales en el interlocutor que no puede percibir a través de sus órganos sensoriales; es elucubración sobre lo que está pensando el otro o para que piense el otro como piensa el actor.

Decimos que en la actividad mental de algunos primates se observan comportamientos que pueden considerarse precursores de esa teoría de la mente, como también se hallan en el comportamiento del niño durante su primer desarrollo.

"Los monos verdes de África Meridional poseen expresiones de aviso diferenciales para las águilas, los leopardos y las serpientes, las cuales no se justifican sólo como diferencia en la emoción de miedo. Las respuestas a grabaciones de las expresiones de aviso sin la asociación con la visión del depredador era idéntica y diferenciada a la llamada en su situación natural. La de leopardo les hacía subirse a los árboles, la de serpiente ponerse en pie y escudriñar la hierba, la de águila esconderse entre los matorrales. Las llamadas transmitían información precisa sobre situaciones específicas de peligro. El principio de que la habituación inhibe la respuesta se aplicó a estas llamadas y se comprueba que la habituación a la llamada de un mono no se transfería a la llamada procedente de otro, con lo que la comparación no se establecía respecto al carácter sonoro, sino al significado de la misma. La identidad del sujeto emisor influía en la interpretación del aviso. Incluso la habituación a una llamada de un sujeto no se transfería a otro tipo de llamada del mismo sujeto. El mono verde, pues, se forma una representación del significado de la llamada. Los sonidos de llamada de los monos verdes se pueden considerar como un sistema semántico rudimentariom.

Pero la plena posesión de la teoría de la mente requiere de la comprensión no sólo de la señal y su significado, sino también la comprensión de ser comprendido, lo que parece que ocurre a partir de los cuatro años ${ }^{17}$; es a partir de entonces cuando la mente humana advierte los estados mentales del otro y obtiene consecuencias de ello para la acción. Los niños anteriores a esa edad, como los primates superiores en sus conductas o los niños autistas, en este caso por carecer de la capacidad de metarrepresentación, no parecen estar interesados en los procesos mentales de sus interlocultores, sino tan sólo en sus conductas fina-

16. Seyfarth, R. M. y ChenEy, D. L. (1993): "Mente y significado en los monos", Investigación y Ciencia, enero, pp. 66 y ss.

17. Gómez, J. C.; SARriÁ, E. y TMarit, J. (1993): "El estudio comparado de la comunicación temprana y la teoría de la mente: ontogénesis, filogénesis y patología", Siglo Cero, septiembre-octubre, pp. 43 y ss. En este trabajo los autores llevan a cabo una descripción pormenorizada de los caracteres y limitaciones de la comunicación prelingüística y su condición de precursora de la teoría de la mente. 
les y sus manifestaciones emocionales; la representación aquí tan sólo afecta a los signos externos de su comportamiento.

Las consideraciones anteriores tienen una importancia fundamental no sólo para orientar la reflexión pedagógica en la acción de formación en edades infantiles sino para componer una teoría de la cultura humana a partir de lo que es su núcleo básico y no meramente su periferia, lo que constituía precisamente el objetivo de este trabajo. La cultura humana arranca propiamente de lo que es la comprensión de la intención del otro (del grupo) dentro de la acción comunicativa, lo que convierte la comunicación social en el instrumento fundamental y específico de la modelación del propio comportamiento. La noción primaria de cultura coincide, pues, con el acto y el proceso interactivo de cooperación en la intención de la acción; atribuir primariamente la noción de cultura al producto de la acción es una sinécdoque. Y ahí se encuentra también el significado de la habitual definición de la acción educativa como acción intencional.

\section{REFLEXIÓN FINAL: LA CULTURA —Y LA EDUCACIÓN— COMO CULTTVO DE LA ACCIÓN SOCIAL}

Las dos vertientes más habituales de estudio de la cultura vienen dadas, de un lado, por el análisis de los procesos colectivos que "cultivan" el comportamiento de los individuos, es decir, el proceso de promoción de la cultura de un individuo (este sentido se encuentra muy próximo al concepto de educación), y, de otro, y siguiendo con la metáfora, por el análisis del "granero de la producción", la cultura patrimonial y construida, la cultura objetiva. Nosotros, interesados aquí sobre todo en la perspectiva que centra su atención en el sujeto más que en el producto de su acción, nos hemos preguntado por lo que entendemos que constituye el proceso más primario y fundamental del suceso y del proceso cultural en el hombre; en este sentido, nos hemos centrado y hemos dado prioridad a los aspectos comunicacionales como fundamentación de los procesos culturales, y concretamente hemos señalado la capacidad de lectura de la intención del interlocutor como característica originaria del proceso cultural, admitiendo de paso que la comunicación no tiene por vehículo meramente el lenguaje, sino todo medio capaz de vehícular el significado, en principio todo cambio de forma y de posición.

Y concluimos ahora dando relevancia al concepto de acción, para incluir en nuestra reflexión no sólo las formas de lenguaje sino también las formas de acción. Los grupos humanos forman colectividades no sólo porque entretejen relaciones de unos con otros en la medida en que comparten los medios de comunicación (la lengua y el sistema de símbolos), sino también porque re-colectan los significados y cristalizan una parte de los mismos (significados compartidos) con lo que en cierta medida fijan el patrón simbólico que orienta la acción; y ello ocurre tanto cuando es acción expresiva (acción comunicativa) como cuando lo es de tipo productivo (acción instrumental) o institucional. De ahí que el fenómeno cultural en su nivel primario de análisis diga relación no sólo, como hemos visto, a la acción comunicativa en vistas a comprender y consensuar el sig- 
nificado (acción en la mente) sino también en vistas a actuar, responder, comprender y consensuar la acción productiva.

Esta modalidad general de acción (acción en el mundo), su oportunidad, la creación de disposición y habilidad, su organización, su valoración y construccióndeconstrucción, recoge y continúa la dimensión comunicativa de la cultura. La propia historia del término cultura en los idiomas latinos vincula el significado no a esencias sino a acciones: partiendo de la acción en general de satisfacer la necesidad más allá de lo que ofrece directamente la naturaleza (acción técnica) y llegando hasta los productos y procesos de la acción, decantándose en el camino los múltiples aspectos comunes porque tienen lugar dentro de un patrón cooperativo, de comunicación y entendimiento, de acción comunicativa y de acción participativa. Y es así como surge la identidad en cuanto resultante de la reciprocidad en el intercambio permanente de oportunidades y habilidades de comportamiento dentro de un contexto.

Todo el equipamiento básico de la especie humana está orientado al ingreso en el mundo de las acciones humanas, lo que significa que el etograma humano implica a "los otros" para conseguir los propios fines como individuo particular; este punto de vista ya lo desarrolló Vygotski admirablemente, señalando que para cada ámbito funcional se presentan dos niveles de acción: uno intra-psicológico y otro inter-psicológico. Pues bien, si lo que caracteriza al ser humano como especie es el comportamiento social complejo, el hecho ontológico interaccional, respecto al cual la cultura es sistema de recursos públicos socialmente compartidos -nosotros hemos situado el punto de separación respecto de las demás especies en lo que hemos denominado, junto con otros autores, como teoría de la mente del otro-, las representaciones colectivas y, en general, los denominados productos culturales carecen de sentido al margen de su uso. Y, en consecuencia, más allá de enfoques antropológicos específicos y problemas sociológicos, el problema pedagógico viene dado por la construcción permanente de sistemas de accesibilidad a estados de co-participación de representaciones, aprovechando la mediación de toda clase de instrumentos y productos; y, aunque algunos calificaron de reproductora a esta acción pedagógica, actuar potenciando la interacción dentro de la red colectiva es potenciar el dinamismo de cambio, sin que pueda ser de otra manera.

Parece ser que el patrón cooperativo ha sido un rasgo seleccionado como ventajoso en la evolución; lo encontramos altamente evolucionado en los primates $^{18} \mathrm{y}$, a medida que evoluciona, va componiendo una parte esencial del entorno en el que se configura el modo de vida de la especie. Algunos ${ }^{19}$ entienden que esta ventaja adaptativa es prioritaria, antecedente causal del desarrollo tecnológico; el desarrollo de la tecnología y la explotación de su potencial de utilidad

18. GOODLAD, J. (1986): En la senda del hombre. Vida y costumbres de los chimpancés. Editorial Salvat, Barcelona. Fossey, D. (1994): Gorilas en la niebla. 13 años viviendo entre los gorilas. Editorial Salvat, Barcelona.

19. Humphrey, N. (1995): Una bistoria de la mente. La evolución y el nacimiento de la conciencia. Editorial Gedisa, Barcelona. 
dependería de la extensión y mantenimiento de relaciones sociales satisfactorias con los otros, más que de la explosión de inventiva de unos sujetos. De ahí que las condiciones para la profundización de la vida social precedan y se configuren anticipándose al desarrollo del sistema tecnológico: inmadurez neonatal, vínculo afectivo, prolongación de la infancia, dependencia de los mayores, complejas estructuras de parentesco, superposición de generaciones...; el escenario biológico fundamental de la vida humana es la "Comunidad colegiada". El ajuste entre intereses, la rivalidad, la dependencia, el consenso social... requieren de una gran finura intelectual para la resolución de los "dilemas" en la toma de decisiones; las especies que se caracterizan por el predominio de estos caracteres son más inteligentes que las demás. En general, la presión que genera la evolución de la complejidad social determina el campo en el que se hace congruente el desarrollo de la tecnología.

En lo anteriormente enunciado se contienen afirmaciones antropológicas de indudable interés para nuestro campo: la "inteligencia" vinculada a la sociabilidad es diferente a la "inteligencia" vinculada a la tecnología. Daniel Dennett ${ }^{20}$ sostiene que a partir de la aplicación de esta forma de discurso a los objetos materiales fue como se configuró la racionalidad instrumental que desarrolla la tecnología, y no al revés. Evolutivamente, es la razón política, por hablar en términos actuales, es decir, la racionalidad ilustrada de la acción comunicativa la que ventajosamente se aplicó a la evolución socio-cultural de la especie humana; no como ahora se pretende afirmar, que la "calidad formal" del pensamiento tecnológico, la racionalidad instrumental de la ciencia es la que contiene el fermento para la resolución de los problemas sobrevivenciales de la Comunidad Humana; según esto, se contiene mayor potencial de racionalidad convivencial en los cuasi-argumentos de la conversación emocionalmente compartida que busca consenso que en las conclusiones de las teorías guiadas por el experimento.

Este planteamiento abre la puerta a un programa de investigación en el que vienen haciéndose ya aportaciones y que algunos denominan con la propuesta de "Inteligencias Múltiples"21. D. Dennet sugiere que la aplicación de la "disposición intencional" en la que operan actitudes, motivos..., y que es la propia del mundo conversacional, a veces se aplica al espacio en el que realmente se actúa con lo que él denomina "disposición para el diseño", dando lugar a todo el campo de las acciones técnicas; tal interferencia no ha sido ni en el proceso evolutivo ni en el cultural, por principio, un perjuicio. El desarrollo de la inteligencia social que se refleja en la complejidad de las estructuras de interacción en los grupos humanos ha sido precisamente el dispositivo que ha potenciado los mecanismos de transmisión cultural, aliviando el costo añadido de la inversión y capitalizando las aportaciones de las individualidades. La calidad mental se refleja primariamente en el orden social, antes que en el orden técnico.

20. DENNETT, D. (1996): Contenido y conciencia. Editorial Gedisa, Barcelona.

21. GaRdNeR, H. (1995): Inteligencias múltiples. La teoría en la práctica. Ediciones Paidós, Barcelona. 


\section{BIBLIOGRAFÍA}

BRILlouin, L. (1956): Science and Information Theory. Academic Press, Nueva York.

BRONCANO, F. (1996): "Información, comunicación y sistemas informativos". En CAFFAREL SERRA, C. (comp.): El concepto de información en las Ciencias Naturales y Sociales. Editorial Universidad Complutense, Madrid.

Brown, V. (1995): Los lenguajes secretos de los animales. Editorial RBA, Barcelona.

Bueno, G. (1996): "Información y causalidad”. En Caffarel Serra, C. (comp.): El concepto de información en las Ciencias Naturales y Sociales. Editorial Universidad Complutense, Madrid.

DennetT, D. (1996): Contenido y conciencia. Editorial Gedisa, Barcelona.

Edelman, G. M. (1994): Biologie de la conscience. Editorial Odile Jacobs, Paris.

FOSSEY, D. (1994): Gorilas en la niebla. 13 años viviendo entre los gorilas. Editorial Salvat, Barcelona.

Frankc, H. G. y Meder, B. S. (1976): Introducción a la Pedagogía Cibernética. Editorial Troquel.

GaRDNER, H. (1995): Inteligencias múltiples. La teoría en la práctica. Ediciones Paidós, Barcelona.

GÓMEZ, J. C.; SARRIÁ, E. y TMARIT, J. (1993): «El estudio comparado de la comunicación temprana y la teoría de la mente: ontogénesis, filogénesis y patología", Siglo Cero, septiembre-octubre, pp. 43 y ss.

GOODLAD, J. (1986): En la senda del hombre. Vida y costumbres de los chimpancés. Editorial Salvat, Barcelona.

HARTLEY, R. (1928): "Transmission of information", Bell System Technical Journal, 7, 535-563.

HuMPHREY, N. (1995): Una historia de la mente. La evolución y el nacimiento de la conciencia. Editorial Gedisa, Barcelona.

MASSEy, J. L. (1971): “Información, máquinas y hombres». En Crosson, F. J. y SAYre, K. M.: Filosofía y cibernética. F. C. E., México.

Maturana, H. y Varela, F. (1990): El árbol del conocimiento. Las bases biológicas del conocimiento bumano. Editorial Debate, Madrid.

Mosterin, J. (1993): Filosofía de la cultura. Ed. Alianza, Madrid.

OCHANDO GONZÁles, M. D. (1996): "Información, genética y evolución". En CAFFarel SERRA, C. (comp.): El concepto de información en las Ciencias Naturales y Sociales. Editorial Universidad Complutense, Madrid.

RiBA I CAMPOS, C. (1996): "Comunicación animal y significado: bases para una zoosemiótica. En CAFFarel SerRa, C. (compl): El concepto de información en las Ciencias Naturales y Sociales, Editorial Universidad Complutense, Madrid.

SeyFARTH, R. M. y ChENEY, D. L. (1993): "Mente y significado en los monos", Investigación y Ciencia, enero, pp. 66 y ss.

SHANnon, C. (1948): "A Mathematical Theory of Communication", Bell System Technical Journal, 27, 379-423, 623-656.

WIENER, N. (1948): Cybernetics. John Wiley \& Sons, Nueva York. 